\title{
MEMORIA DE CARLOS S. NINO: TRES TEXTOS DESCONOCIDOS
}

a inesperada desaparición de Carlos Nino el pasado 29 de agosto, con toda la carga de sinsentido absurdo que tienen siempre estas tremendas realidades cotidianas, ha suscitado entre nosotros una pesadumbre difícil de expresar. Nos hemos beneficiado durante muchos años de sus escritos, sus enseñanzas, sus discusiones incesantes, su prodigiosa inteligencia. Y por encima de todo eso estaba el amigo, el debatidor incansable, el colaborador de tantas tareas académicas, intelectuales, políticas, que no sentía nunca pereza por saltar al avión cuando se le reclamaba. Su asombrosa capacidad de trabajo, de iniciativa, no puede explicarse sin ese imperativo de integridad moral que le llevó a tratar de practicar siempre la ética que postulaba: en la universidad, en la política, en la cooperación internacional. No podemos hurtarnos a la sensación de que quizá fue eso lo que le costó la vida. La pérdida que ello supone para la teoría del derecho, para la filosofía moral o para la reflexión política no es fácil de calibrar. Si en nuestro medio ambiente es tan patente su ausencia, podemos imaginarnos lo que será el vacío que habrá dejado en la Universidad argentina.

Nuestro homenaje a su memoria no puede ser otro que continuar nuestro diálogo con él y seguir debatiendo su pensamiento. Para hacerlo así hemos rescatado tres textos inéditos, producto de otras tantas colaboraciones suyas en nuestras tareas. El primero de ellos es la transcripción de su intervención en el simposio que celebramos con los representantes americanos del movimiento Critical Legal Studies. Se celebró en Madrid, los días 2 a 5 de junio de 1992, en el Centro de Estudios Constitucionales, patrocinado por el Real Colegio Complutense de Harvard, el Departamento de Filosofía de Derecho de la Universidad de Alicante y la Harvard Law School. La ocasión era importante porque no teníamos noticia de ningún anterior encuentro parecido en España. Desde el primer día la temperatura 
del debate empezó a elevarse ostensiblemente. Aunque nuestros interlocutores estaban quizá acostumbrados a ejercer la crítica de los demás con cierta autocomplacencia, no parecían tan duchos en soportarla respecto de sí mismos. El formato del encuentro era innovador, pero no contribuía a limar asperezas. En lugar de presentar uno su propia ponencia tenía que escuchar cómo uno de sus interlocutores del otro bando hacía un análisis crítico de la misma. Por más que les fue advertido que entre nuestros hábitos intelectuales más característicos figuraba el debate y la disección poco piadosas, las cosas acabaron por tensionarse quizá demasiado. Incluso no faltaron las impertinencias de ambos lados. Intelectualmente fue muy estimulante. Tanto que, al final, Carlos Nino decidió modificar su plan inicial para intentar exponer cuál era su concepción de la filosofía jurídica y en qué podía emparentarse con la corriente de los Critical. Cuando acabó, todos fueron unánimes: querían una copia de la grabación de su charla. Con todas las dificultades e imperfecciones de una transcripción, ahí la ofrecemos.

El segundo texto es algo más antiguo. Corresponde a su ponencia en el IV Congreso Iberoamericano de Derecho Constitucional, celebrado en Madrid los días 27 a 30 de septiembre de 1988 y patrocinado por la Fundación Friedrich Ebert, la Asociación Iberoamericana de Derecho Constitucional y el Centro de Estudios Constitucionales. El tema más debatido del Congreso fue el de los problemas del Presidencialismo en América Latina. Carlos Nino estaba muy interesado en él. Conscientes de esa inquietud habíamos conseguido que su intervención se produjera en el plenario del último día. Pero hubo quien palideció cuando al llegar al aeropuerto nos tendió, como ponencia, veinte hojas arrugadas con un garabateado informe que acababa de escribir en el avión. La inquietud, sin embargo, se disipó en cuanto empezó a hablar. Con rara maestría y familiaridad circuló por aspectos empíricos, institucionales, de ciencia política y de filosofía moral hasta completar una argumentación contundente y limpia. El texto que ofrecemos fue, por fortuna, desentrañado, corregido y completado por él mismo.

El tercer texto se corresponde con el término que envió en mayo de 1993 como contribución al volumen Derecho y Justicia de la Enciclopedia Iberoamericana de Filosofía. Le había sido asignada la voz «Justicia», y algunos dijimos que en virtud de ello podría haber algo más de flexibilidad con las limitaciones de espacio y de tiempo. Tres semanas después llegó su trabajo. Fue el primero en llegar. En su carta escribía: «Me costó mucho comprimir en 12 páginas un desarrollo sobre el concepto de justicia. Espero que el resultado sea aceptable. Por lo menos he cumplido con el tiempo. Ando viajando mucho. La semana pasada volví de Italia y mañana me voy a San 
Diego, EE.UU.». Todo un retrato. Reproducimos el texto agradeciendo vivamente a los responsables de la Enciclopedia que nos hayan autorizado a publicarlo antes que el volumen correspondiente.

Al publicar aquí estos tres textos, tan aparentemente dispares y heterogéneos pero, sin embargo, tan inequívocamente suyos, sólo nos proponemos recuperar por un momento su voz fina y suasoria como una pequeña contribución y un cálido tributo a la memoria de quien fue un amigo y un maestro. 